\title{
Prevention of Traumatic Brain Injury in the United States: Significance, New Findings, and Practical Applications
}

\author{
Tolulope A. Fatuki ${ }^{1}$, Valeriy Zvonarev ${ }^{2}$, Aaron W. Rodas ${ }^{3}$
}

1. Psychiatry/Medicine, Spartan Health Sciences University, Vieux Fort, LCA 2. Psychiatry, University of MissouriKansas City, Hospital Hills Campus, Kansas City, USA 3. Internal Medicine, Lower Bucks Hospital, Bristol, USA

Corresponding author: Valeriy Zvonarev, zvonarevval@gmail.com

\begin{abstract}
Traumatic brain injury (TBI) prevention programs aim to reduce trauma-related head injuries across the United States. In addition to epidemiological challenges, patients with TBI have a greater burden of disease and worse health outcomes than the general population. In these circumstances, the prevention of TBI is an important element in reducing the occurrence of post-traumatic health consequences in all settings and beyond. We completed a high-quality overview of TBI prevention programs using the public health approach to identify the most compelling risks to individuals through surveillance, data analysis, and field assessment. We explored the evidence-based programs that are proven to help individuals reduce the risk of TBI. To date, TBI programs have been very efficient, as evidenced by a sustained downturn in TBI incidence. However, recent socioeconomic and epidemiological challenges in the United States are affecting state and local TBI prevention efforts. This article is focused on strategies and solutions to reduce risks and/or consequences associated with head injuries from motor vehicle accidents in New York City. We believe this report is essential to guide the design and implementation of adequate preventive strategies and providing safe and high-quality patient care across all settings where healthcare is delivered.
\end{abstract}

Review began 09/25/2020 Review ended 10/19/2020 Published 10/28/2020

() Copyright 2020 Fatuki et al. This is an open access article distributed under the terms of the Creative Commons Attribution License CC-BY 4.0., which permits unrestricted use, distribution, and reproduction in any medium, provided the original author and source are credited.
Categories: Neurology, Preventive Medicine, Public Health

Keywords: tbi, trauma, brain injury, prevention, public health, mva

\section{Introduction And Background}

\section{Introduction}

Traumatic brain injury (TBI) is the most common type of neurosurgical pathology and is the leading cause of morbidity and disability in adults up to 45 years old. According to some estimates, TBI costs the global economy approximately US $\$ 400$ billion per year [1]. Currently, there is a pronounced trend of increasing incidence of TBI, which primarily is due to man-made factors' increased impact on human beings, an increase in criminal injuries, and natural disasters [2].

TBI entails damage to the brain and other intracranial formations (cerebral membranes, blood vessels, cranial nerves) from mechanical force against the head. According to statistics, secondary injuries were recorded in about $90 \%$ of patients who died from brain injury. However, even in cases of severe TBI, secondary brain damage can be prevented with timely and adequate therapy [3].

It should be noted that mild TBIs are also a serious medical and social problem, despite the fact that they are characterized by unpronounced neurological symptoms and a relatively short rehabilitation period. Estimated annual incidence of light TBIs worldwide is 100 to 300 people per 100,000 people. Furthermore, significant statistical discrepancies are due to the specificity of diagnostic criteria in different countries [4]. In particular, the data on the incidence with which patients seek treatment for TBIs varies from $0.3 \%$ to $44 \%$, and the average length of hospital stays for TBIs varies from three days (Norway) to 21 days (Malta) [5].

Due to the lack of uniform approaches to the classification and diagnosis of TBIs, many cases of light TBIs lack professional attention, which significantly increases the risk of developing chronic neurological and psycho-physiological consequences from trauma. However, numerous studies have shown that the earliest possible medical intervention after a mild TBI significantly reduces the likelihood of delayed chronic effects $[5]$.

All the above make it important to prevent TBIs, as well as improve methods of treating TBIs of differing severity. In this regard, this article aims to compare classical and modern approaches to the prevention of TBIs. As the main criteria for the efficacy of prevention programs, we primarily assessed their scope, the need for financial investments, and changes in targets as a result of program implementation.

Specifically, this type of analysis that we conducted serves to offer partial insight into the actual extent to 
which traumatic brain injuries have become a threat to the general public in New York City.

The following objectives have been set to achieve this goal:

- summarize epidemiologic data on TBIs,

- describe the main measures aimed at preventing TBIs,

- consider innovative TBI prevention and prophylactic programs,

- conduct a comparative analysis of several TBI prevention programs' efficacy,

- describe and analyze the role of motor vehicle accidents and/or dangerous driving behavior in TBI incidence across New York City (NYC),

- attempt to analyze the COVID-19 pandemic's impact on driving behavior and statistics in NYC, and

- assess these changes' influence on TBI case.

\section{TBI statistics and epidemiology}

TBIs account for $30 \%$ to $50 \%$ of total traumatic mortality rates. The total mortality rate caused by TBIs, including light and moderate TBIs, is $5 \%$ to $10 \%$. Most TBIs occur among people ages 15 to 24 and those over $75[6,7]$. In the United States, the incidence of TBIs varies from region to region and from one social group to another, with a range of 108 to 295 cases per 100,000 people. The highest incidence of TBIs was recorded among men and young people ages 15 to 24 years old, as well as in the older age group [8].

\section{Basic measures for TBI prevention}

Primary prevention of TBIs aims to avoid the injury itself, while secondary prevention aims to mitigate the severity of consequences in case of injury.

Primary prevention programs include interventions that improve vehicle and road infrastructure safety, as well as workplace safety, while secondary prevention programs are based primarily on improving the trauma care system. A practical way to improve primary prevention programs' efficacy is to target certain risk groups (e.g., programs targeting drivers and cyclists, single elderly people, and children in socially disadvantaged situations) $[9,10]$. Statutory restrictions on speed limits for road users, improvements in road infrastructure (e.g., separation of pedestrians and cyclists from motorized vehicles), and improved street lighting have been recognized as effective national strategies for TBI prevention [11].

Secondary non-medical prevention strategies include the use of protective headgear and protective systems in vehicles. Mandatory use of a helmet significantly reduces the number and severity of head injuries for both motorcyclists and bicyclists. For example, in Taiwan, the adoption of the Motorcycle Helmet Law in 1997 reduced the number and severity of motorcycle riders' TBIs by 33\%. Educational programs aimed at disseminating information on both preventing TBIs and patient care procedures after TBIs also make an important contribution to preventing TBIs [1].

The main medical measures in secondary prevention of TBIs are based on notions of pathogenetic mechanisms of primary and secondary brain damage caused by mechanical impact. Modern neuroimaging techniques also currently are being used to diagnose TBIs, but in patients with mild TBIs, in approximately $10 \%$ of cases, computed tomography may fail to detect morphological signs of brain injury [12]. MRI scans are a more sensitive method of visualizing structural changes, especially if they are performed shortly after TBIs [3].

In accordance with modern ideas about the pathogenesis of TBIs and their complications, processes such as inflammation, receptor-mediated damage, oxidative stress, and brain damage mediated by calcium ions make a major contribution to the destructive processes that occur in brain tissue [13].

It should be noted that the quality of care that a patient receives during the early stages of TBI can be viewed as the primary contributor to patients' recovery, as well as to reductions in patients' lifetime healthcare costs [14]. In particular, among TBI patients who were not hospitalized for treatment, approximately twice as many individuals reported restrictions on activity and low life satisfaction compared with patients hospitalized for TBI treatment [15].

After discharge from the hospital, medical and social support aimed at preventing eventual delayed negative consequences comes to the fore [16,17]. These interventions include medication therapy and rehabilitation [4]. The use of alcohol and psychoactive substances is absolutely contraindicated for patients after TBIs, as 
they can exacerbate existing neurological and psycho-physiological consequences from TBIs significantly [18].

\section{TBI prevention and prophylaxis programs}

One of the applications of the most inclusive programs implemented at the national level is related to the monitoring of epidemiological indicators of TBIs and identification of their main risk factors. In 1996, the U.S. Congress passed Public Law 104-166, which instructed the federal Centers for Disease Control and Prevention (CDC) to implement TBI prevention projects, which included developing a unified reporting system. This and other tasks related to TBI prevention have received an annual budget of US $\$ 3$ million between 1997 and 1999, some of which was spent to develop a unified system for collecting information on the incidence and prevalence of TBIs, as well as on TBI-related disabilities in the United States. Until the late 1990s, TBI monitoring systems were implemented in 15 states (Colorado and South Carolina joined later). The integration of data collected from different states based on common clinical criteria has resulted in standardized multi-level TBI assessments. In 2005, TBI surveillance was expanded with additional funding from the Violence and Trauma Prevention Program (Core VTPP), bringing the number of states participating in the program to 30 . In addition, 11 states provided the necessary data voluntarily. At the same time, the list of collected data was expanded.

This system's implementation has enabled the CDC to identify the most frequent concomitant diseases (e.g., hypertension) and concomitant injuries among those ages 65 and over who have suffered TBIs from falls. Between the late 1990s and mid-2000s, some states used this system to conduct studies on TBIs' long-term effects [19]. Currently, the TBI program is funded in 20 states, and its data are used widely to analyze different aspects of TBI and confirm that TBI indicators can vary greatly from region to region, even within one country. This needs to be taken into account when analyzing the main risk factors for TBIs. The contribution of different factors to TBI statistics also can vary significantly, which prevents the mechanical transfer of epidemiological data accumulated in one country to other countries, especially if they demonstrate different levels of economic development [20]. Accordingly, the development of national systems for monitoring TBI epidemiology is likely to be viewed as one of the most important modalities of TBI prevention.

Although experts have deemed the algorithm that the CDC developed to be effective, some studies in recent years have demonstrated that its "resolution capacity" can be expanded [21]. In particular, this is evidenced by the comparison of the TBI epidemiological data obtained using the CDC algorithm and the Rochester Epidemiology Project algorithm. The authors estimated the annual TBI incidence per 100,000 people for the years 1987-2000 in Olmstead County, Minnesota. The TBI incidence calculated based on the Rochester Epidemiology Project algorithm and the analysis of medical records was 558 (528 to 590, for a 95\% probability level), while the one calculated based on the CDC algorithm was only 341 (331 to 350 , for a $95 \%$ probability level). However, only $40 \%$ of cases with TBI symptoms have been recorded in the CDC system [22].

A special place among TBI prevention programs is occupied by those that aim to improve safety among road users. For example, a significant reduction in the mortality rate from TBIs caused by car accidents has been recorded in several countries among people ages 15 to 24 after implementing phased licensing of new drivers [23].

The CDC has developed a project aimed at selecting the most promising areas for reducing TBIs caused by accidents. The project is based on an interactive online Priority of Intervention and Cost Calculator for States (PICCS). The calculator allows you to select the most effective measures to prevent TBIs caused by accidents from a package of 14 effective tools (seat belt laws, bicycle helmets laws, etc.). PICCS allows for calculating the expected number of injuries and lives saved at the national level, the economic benefits from increasing the number of injuries and lives saved, and the costs of implementing specific measures [19]. The tool is offered publicly to support state and local communities in making evidence-based resource-allocation decisions to help prevent motor-vehicle-related injuries. The tool offers 14 motor vehicle strategies to help reduce motor vehicle injuries. Of the 14 motor vehicle strategies that the tool offers, the State of New York currently uses eight of these 14 motor-vehicle-injury prevention strategies. The six that are not currently in use are "Increased Seat Belt Fines," "License Plate Impoundment," Seat Belt Enforcement Campaign," “InPerson License Renewal," "Saturation Patrols," and "Vehicle Impoundment." Thus, there is still room for improvement in the State of New York to reduce the cost burden from motor vehicle injuries. For example, the "Increased Seat Belt Fines" and "Seat Belt Enforcement Campaign" can be implemented to increase the use of seat belts. In 2014, the DMV's Statewide Statistical Summary noted that $2.7 \%$ of individuals did not use seat belts, totaling 16,068 individuals. Furthermore, the data regarding 57,085 individuals remain unknown. It is important to increase the number of people using seat belts because New York State road statistics in 2014 noted that unrestrained vehicle occupants were three times more likely to be diagnosed with TBIs. The statistics also noted that alcohol-related crashes were associated with the highest risk of TBI. The State of New York already has sobriety checkpoints implemented, but they also can implement saturation patrols to reduce alcohol-related vehicle crashes further [24,25]. 
aimed at improving motorcyclists and bicyclists' safety, including through the enforcement of mandatory helmet laws. Such programs are most effective in countries with extensive use of motorcycles and bikes, e.g., in Southeast Asia. For example, a comprehensive helmet policy launched in Vietnam in 2007 prevented some 2,200 deaths and 29,000 head injuries, saving \$18 million in direct emergency medical care costs. The national program was based on the adoption in 2007 of a package of laws requiring that all riders wear helmets. These laws have expanded the scope of mandatory use of helmets for all road users (not only motorcycle drivers, but also their passengers), significantly increased penalties for refusing to wear a helmet, and provided for several enforcement measures. Fines for failure to wear a helmet have increased from US $\$ 2$ to $\$ 5$ to US $\$ 11$ to $\$ 22$ (i.e., to about 30\% of average monthly per capita income). The average market price for a standard helmet is around $\$ 17$. As a result of application of these measures, helmet use rose from $30 \%$ to $93 \%$ in the first few months, and motorcycle-related deaths fell from $29 \%$ to $14 \%$ [26].

Protective helmets' positive role also has been corroborated through other authors' findings. Cassidy coauthored research that analyzed two original studies that had been conducted in Australia and in the United States (Seattle, Washington) between 1986 and 1992 [27]. Analysis of the statistics in both cases confirmed that cyclists who used protective helmets were significantly less likely to suffer from TBIs. In Canada, hospital admissions to pediatric wards for children and adolescents with head injuries have decreased by $45 \%$ since the enactment of mandatory helmet laws for cyclists. Two other studies that Cassidy analyzed confirmed helmets' efficacy in preventing TBIs. A meta-analysis of the data published in the early 2000s also confirmed this conclusion [27].

Another modality of TBI prevention is prophylaxis programs related to sports and recreation. This modality is enhanced by the fact that the highest incidence of TBIs occurs among youngsters and adolescents [28].

To improve the situation, the CDC has developed and implemented several programs aimed at informing the population about TBIs and changing public attitudes toward TBIs, an example of which is the well-known HeadsUp program [19].

HeadsUp targets young athletes, parents, health workers, coaches, and teachers to prevent, recognize, and respond adequately in the event of a TBI. HeadsUp focuses on issues such as TBI prevention and first aid in case of a suspected TBI. The program is based on the transformation of the latest scientific achievements in neurology and education into special educational products specifically designed for the target audience. To date, the CDC has created over 50 such educational products, distributed over 6 million copies of HeadsUp commercials, and prepared over 3 million trainers. Positive changes in high school students' knowledge levels and behavioral skills related to preventing TBIs have been confirmed [29].

The HeadsUp initiative prepared a tool kit, "Brain Injury In Your Practice,” for health care professionals, but has expanded to provide educational resources that focus on sports programs and schools to reduce the risk of brain injuries, especially in children and teens. One study observed the reach of HeadsUp online material and courses and assessed participants' knowledge from May 2010 to July 2013. An interesting finding was that New York was one of the states with the lowest participation rates [30]. This does not indicate that coaches in the State of New York are not well-versed on the topic because they may be utilizing different materials to learn and handle concussion management. However, when examining the State of New York, in December 2019, "Public Health Law: Section 2595 Football programs; information on concussions” was passed. It requires all tackle-football programs in the State of New York to provide resources and information packs about brain injuries (concussions and sub-concussive blows) to all parents of children who are participating in tackle-football programs. The State of New York also launched its "When in Doubt...Take Them Out!” prevention campaign, which provides professionals (e.g., coaches, athletes, school administrators) and parents with information to help prevent, recognize, and manage concussions.

The CDC has developed the STEADI program to prevent TBIs in senior citizens caused by falls. STEADI focuses on health professionals working with older people and aims to identify and address modifiable risk factors. By CDC estimates, if 5,000 STEADI-compliant healthcare workers were to examine six million patients over a five-year period, one million falls could be prevented, and $\$ 3.5$ billion in direct healthcare costs could be saved [31]. STEADI was one of the initiatives implemented in the State of New York in 2012 that focused on identifying patients' fall risks, assessing any modifiable fall-risk factors, and intervening to reduce fall risks with community and clinically based strategies [32]. In 2014, there were reportedly 29 million falls, and by 2030, one in five Americans will be at least 65 years old. Elderly Americans are more prone to falling, but they are also more susceptible to fall-related injuries, the most common cause of nonfatal trauma-related hospital admissions among older adults. Chronic medical conditions such as cognitive and/or visual impairment, age-associated changes in strength and balance, polypharmacy are also associated with increased risk of falls [32].

In New York, STEADI was initiated in 17 primary care clinics, which soon demonstrated that roughly $70 \%$ of older patients were being screened for falls after implementation [32]. Furthermore, another article demonstrated that STEADI can be implemented easily with proper guidance, utilizing the Kotter Framework, an eight-step process for integrating health care initiatives within organizations [33]. The article noted that the focus for a successful initiative depended on aligning a workflow with the usual clinic flow, integrating 
the STEADI protocol into the EHR, testing the workflow in small sessions before widespread implementation, and implementing in-person training to educate personnel on falls. Once the STEADI protocol was implemented across several teams, within the first three months, they screened 360 patients, i.e., $19 \%$ of eligible patients [33]. Prior to this, health care providers had no other fall-screening documents. This study alone offers the opportunity to implement STEADI in all primary care clinics across the State of New York.

Another area of development for prevention programs within the TBI context is the prevention of negative TBI consequences. Such programs are based on identifying factors that increase the risk of maintaining or enhancing symptoms that become more tangible after TBI. One of the preventive programs based on risk factors, the Early Response Brain Injury Service (ERBIS), was implemented at GF Strong Rehabilitation Center in 2003-2004. During the research period, 117 (16.9\%) of the TBI individuals included in the program were identified as at risk of prolongation of symptoms and met with the community facilitator for a lecture. During the observation period, these people were divided into two groups: 33 out of 117 people (28\%) had permanent post-traumatic symptoms requiring specialized attention, while 84 people (72\%) were able to cope with permanent symptoms on their own and gradually returned to their previous routines. Patients who received additional professional help noted an improvement in symptoms after six to 12 months [4].

As the statistics show that TBI is viewed as a factor that increases the risk of suicidal behavior, programs aimed at preventing suicide attempts are of high importance, especially among patients who suffered TBI from military service. Brenner et al. [34] suggested recommendations for developing such programs to be seriously considered by lawmakers.

Modern means of communication currently are used to prevent effects from TBIs. An example of this is a post-discharge TBI patient-support program based on text-message exchanges (SMS). As part of this program, the patient makes a self-assessment of his/her symptoms three times a day in the form of an SMS message, e.g., "9 a.m.: headaches; 1 p.m.: concentration difficulties; 5 p.m.: irritability or anxiety.” In a study of a group of 43 patients who received such support, it was shown that the patients themselves appreciated the importance of this form of support. Compared with the control group, participants in the program had a lower incidence of headaches, attention disorders, irritability, and anxiety. There was also a downward trend in average intensity scores for all the disorders studied, but the differences with the control group were unreliable [35].

\section{Review}

\section{Comparative analysis of TBI prevention programs' efficacy}

Thus far, a large number of TBI prevention programs have been developed and are at different stages of implementation, varying across a whole range of parameters and covering work with the main TBI risk factors. A brief comparative description of the major programs is presented in Table 1. 


\section{Cureus}

\begin{tabular}{|c|c|c|c|c|}
\hline Program title & Target group & Program objective & $\begin{array}{l}\text { Implementation } \\
\text { level }\end{array}$ & Nature of preventive measures \\
\hline 1 & 2 & 3 & 4 & 5 \\
\hline \multicolumn{5}{|c|}{ Programs almed at reducing I $\mathrm{B} / \mathrm{Incla}$ ence } \\
\hline $\begin{array}{l}\text { CDC } \\
\text { epidemiological } \\
\text { system }\end{array}$ & 20 U.S. states & TBI epidemiology monitoring & $\begin{array}{l}\text { Implemented } \\
\text { continuously at the } \\
\text { federal level }\end{array}$ & $\begin{array}{l}\text { Epidemiological data collection and } \\
\text { risk factor identification }\end{array}$ \\
\hline $\begin{array}{l}\text { Rochester } \\
\text { Epidemiological } \\
\text { Project }\end{array}$ & Minnesota & TBI epidemiology monitoring & $\begin{array}{l}\text { Implemented } \\
\text { continuously at the } \\
\text { federal level }\end{array}$ & $\begin{array}{l}\text { Epidemiological data collection and } \\
\text { risk factor identification }\end{array}$ \\
\hline PICCS & $\begin{array}{l}\text { Administrative } \\
\text { authorities }\end{array}$ & $\begin{array}{l}\text { Selection of the most effective } \\
\text { measures to prevent TBI }\end{array}$ & $\begin{array}{l}\text { Implemented } \\
\text { continuously at the } \\
\text { federal level }\end{array}$ & $\begin{array}{l}\text { Online calculator for calculating } \\
\text { efficiency and economic indicators }\end{array}$ \\
\hline HeadsUp & $\begin{array}{l}\text { Coaches, athletes, } \\
\text { parents }\end{array}$ & $\begin{array}{l}\text { Raising awareness of } \mathrm{TBI} \text { and } \\
\text { prevention measures }\end{array}$ & $\begin{array}{l}\text { Implemented } \\
\text { continuously at the } \\
\text { federal level }\end{array}$ & $\begin{array}{l}\text { Wide distribution of specially } \\
\text { prepared training aids }\end{array}$ \\
\hline STEADI & Senior citizens & $\begin{array}{l}\text { Creating a safe environment } \\
\text { that reduces the risk of falling }\end{array}$ & $\begin{array}{l}\text { Implemented } \\
\text { continuously at the } \\
\text { federal level }\end{array}$ & $\begin{array}{l}\text { Living arrangements at home, } \\
\text { medical support }\end{array}$ \\
\hline \multicolumn{5}{|c|}{ it reducing the severity of TBls and their consequences } \\
\hline $\begin{array}{l}\text { Programs related } \\
\text { to the use of } \\
\text { protective helmets }\end{array}$ & $\begin{array}{l}\text { Motorcyclists, } \\
\text { bicyclists }\end{array}$ & $\begin{array}{l}\text { Reduce the likelinood of a } \\
\text { heavy TBI in the event of an } \\
\text { accident }\end{array}$ & $\begin{array}{l}\text { Implemented in } \\
\text { several countries at } \\
\text { the federal level }\end{array}$ & $\begin{array}{l}\text { Adoption of laws governing the use } \\
\text { of helmets }\end{array}$ \\
\hline ERBIS & Patients with TBI & $\begin{array}{l}\text { Reduce the risk of } \\
\text { development and the severity } \\
\text { of complications after the TBI }\end{array}$ & $\begin{array}{l}\text { GF Strong } \\
\text { rehabilitation center } \\
\text { 2003-2004 }\end{array}$ & $\begin{array}{l}\text { GF Strong rehabilitation center } \\
2003-2004\end{array}$ \\
\hline $\begin{array}{l}\text { Suicide prevention } \\
\text { program }\end{array}$ & $\begin{array}{l}\text { Patients with TBIs } \\
\text { caused during } \\
\text { military service }\end{array}$ & $\begin{array}{l}\text { Reduce the risk of suicidal } \\
\text { behavior }\end{array}$ & $\begin{array}{l}\text { Local, time limited } \\
\text { by research time } \\
\text { frame }\end{array}$ & $\begin{array}{l}\text { Condition monitoring and } \\
\text { psychological support for the } \\
\text { patient }\end{array}$ \\
\hline Support via SMS & Patients with TBI & $\begin{array}{l}\text { Reduce the riSk of } \\
\text { development and the severity } \\
\text { of complications after the TBI }\end{array}$ & Local & $\begin{array}{l}\text { Selt-assessment of personal status } \\
\text { in the form of responses to } \\
\text { automatic SMS messages }\end{array}$ \\
\hline
\end{tabular}

\section{TABLE 1: Main characteristics of TBI prevention programs}

Abbreviations: TBI: traumatic brain injury; CDC: Centers for Disease Control and Prevention; PICCS: Priority of Intervention and Cost Calculator for States; STEADI: Stopping Elderly Accidents Deaths and Injuries; ERBIS: the Early Response Brain Injury Service; SMS: short message service.

We can see that the programs presented in Table 1 significantly differ from each other in their goals, scales, used methods of intervention, etc., which makes the comparison of their efficacy difficult. In addition, basic epidemiological data collection programs are difficult to assess in terms of efficacy because they do not actually impact the target group, but without these programs, it would not be possible to identify groups and risk factors, and, thus, further prevention activities.

In this regard, in Table 2, we present a comparative assessment of the programs reviewed using the criteria that we consider the most relevant. 


\section{Cureus}

\begin{tabular}{|c|c|c|c|}
\hline Program title & $\begin{array}{l}\text { Population } \\
\text { outreach }\end{array}$ & $\begin{array}{l}\text { Financial } \\
\text { costs }\end{array}$ & Effect on targets \\
\hline CDC epidemiological system & +++ & +++ & Does not involve direct influence \\
\hline Rochester Epidemiological Project & ++ & ++ & Does not involve direct influence \\
\hline PICCS & ++ & ++ & Does not involve direct influence \\
\hline HeadsUp & ++ & ++ & ++ \\
\hline STEADI & ++ & ++ & ++ \\
\hline $\begin{array}{l}\text { Programs related to the use of protective } \\
\text { helmets }\end{array}$ & +++ & + & +++ \\
\hline ERBIS & + & + & + \\
\hline Suicide prevention program & + & + & No data \\
\hline Support via SMS & ++ & + & $\begin{array}{l}++ \text { (according to subjective perceptions of } \\
\text { patients) }\end{array}$ \\
\hline
\end{tabular}

\section{TABLE 2: Comparative description of prevention programs' impact on TBI statistics}

Abbreviations: TBI: traumatic brain injury; CDC: Centers for Disease Control and Prevention; PICCS: Priority of Intervention and Cost Calculator for States; STEADI: Stopping Elderly Accidents Deaths and Injuries; ERBIS: the Early Response Brain Injury Service; SMS: short message service.

Based on the data in Table 2, as well as on the data from the analyzed publications, it is possible to consider the programs related to the use of protective helmets to be the most effective among the primary prevention programs. Indeed, these programs do not require significant financial investment (on the contrary, violators will replenish local budgets by paying fines for violations of the law) and cover the entire population of the country or state. Statistics from different countries provide strong evidence of such programs' efficacy.

From our perspective, programs like HeadsUp and STEADI are highly efficient. From the perspective of the possibility of distributing such programs in rural areas, STEADI can be assumed to be more cost-effective, as it would require less funding because older people are overwhelmingly under the supervision of a district doctor, relatives or social workers. Training doctors and social workers under this program may be sufficient during the first stages of its implementation, but the HeadsUp program envisages substantial investments in the preparation of special training materials.

Among secondary prevention programs, the most promising is the support program through SMS messages. This technology is currently available, relatively inexpensive, and can reach a significant number of patients. Simultaneously, the patients themselves greatly appreciate such a support program. There is no doubt that this program's efficacy needs to be confirmed, but even with only subjective improvements in patients' conditions, it can play an important role in their rehabilitation process.

\section{Improvements in dangerous driving behavior as a new mode of TBI prevention}

Motor vehicle crashes are the most common cause of emergency room visits, hospitalizations, and deaths related to traumatic brain injury among people ages 15 to 34, according to a 2013 CDC report. Furthermore, more than $14 \%$ of cases that the CDC reports are the direct result of automobile accidents. Non-fatal TBIs are the leading cause of hospitalization among those ages 15 to 44 [36].

Reckless driving, that is, using a car in such a way that it "unreasonably interferes with the free and proper use of the public highway" or endangers others, is illegal under New York State law. Additionally, road rage, as defined by the AAA Foundation for Traffic Safety, is still very common among New York drivers [37]. Any unsafe driving performed intentionally and with disregard for safety - such as cutting people off, hitting another car, or physically or verbally assaulting other road users - potentially may lead to traumatic head injuries. Unlike sports or military aspects, little research has been done on the link between car crashes and TBIs.

This part of our research is designed to assess the hypothesis that aggressive driving behavior among NYC drivers may affect the prevalence of traumas and head injuries. The present analysis aimed to: (1) assess driving behavior characteristics in NYC drivers without cognitive impairments and identify relationships between TBIs and/or traumatic outcomes and on-road behavior, and (2) investigate whether traffic and 
driving restrictions may improve NYC drivers' behavior. We attempted to determine the efficacy of the "pause" in predicting the likelihood and frequency of TBI cases during the pre-COVID-19 and lockdown periods. We assumed that tracking data for behavioral trends could improve public safety and add another layer of insight in identifying important aspects needed for improvement.

It has been suggested that COVID-19-related traffic restrictions affected the incidence of TBIs nationwide, but this has not been proven. Using various public resources, we attempted to predict the COVID-19 lockdown's impact on driving behavior and TBI cases in New York City. The incidence of car accidents and/or traumatic outcomes in this study has been characterized by this population in terms of borough, time, and crash-related factors. In addition, some characteristics most predictive of TBI during the prequarantine and lockdown periods have been identified and compared.

\section{COVID-19 restrictions' estimated impact on driving behavior and TBI incidence}

Most extant studies on the incidence of TBI are inconclusive, and none specifically has discussed brain injuries attributable to motor vehicle crashes and traffic changes during the past three months. Interestingly, a recent study conducted at NYU found mappable correlations between six months of driver behavior data and the numbers related to car crashes. There was a $71 \%$ overlap between the location of reckless driving behaviors and motor vehicle accidents around New York City. Moreover, researchers confirmed a $68 \%$ correlation between fast acceleration and aggressive driving/road rage collisions, along with hard braking and following-too-closely collisions [38, 39].

COVID-19 lockdown restrictions implemented nationwide affected car traffic in many ways. For example, the location technology company TomTom released a traffic index with data from hundreds of U.S. cities showing how these restrictions affected New York City life. It is clear that traffic levels fell sharply in the final weeks of March-April 2020. Unfortunately, the number of deadly automobile crashes in the United States rose dramatically in March-April 2020, even though the number of miles driven decreased due to lockdown time-based traffic restriction (TBR). The National Safety Council concluded that the number of fatal crashes per 100 million miles driven rose an "alarming" 14\% compared with March 2019, but the number of traffic deaths in the United States fell by $8 \%$ in March compared with 2019 due to an $18.6 \%$ drop in miles traveled. While the number of fatal outcomes declined in March 2020, they were still up about $2 \%$ for the first three months of 2020. Moreover, several states reported significant increases in speeding. For example, in Los Angeles, speeds were up by as much as $30 \%$ on some streets, while authorities in other major metropolitan areas reported drivers traveling at over $100 \mathrm{mph}$ (Tables 8-10 in Appendices).

Other data provided by Streetlight (www.streetlightdata.com) show significant changes in driving behavior. New Yorkers traveled up to 120.3 million vehicle miles in all five boroughs on March 2. These numbers are very typical for this time of year and characterize the workday before COVID-19. Interestingly, by March 23, the first weekday of the "pause," the number fell to 26.89 million vehicle miles travelled (VMT), or nearly $78 \%$ less. Moreover, total VMTs had dropped to 21.63 million one week later. In contrast, VMTs totaled 29.24 million on May 1, and total VMTs jumped again - by $17 \%$ - on May 8 . These numbers are significantly higher than the data obtained at the end of March even though nothing had changed in the state's lockdown restrictions $[40,41]$. Estimated vehicle miles traveled were down between $78 \%$ and $92 \%$ compared with January $2020[42]$.

In accordance with New York City Mayor Bill de Blasio's mandates, the city closed several streets to car traffic, expanded sidewalks, and arranged additional bike lanes to provide New Yorkers with extra space to maintain social distancing. New York City Council members also passed a bill to devote approximately 75 miles of city streets to pedestrians throughout the closing. However, this proposal's safety aspect is still questionable, given the city's population density [43].

Most people appear to self-monitor their driving behavior, especially during challenging circumstances, such as the pandemic. However, not all drivers can control their driving behavior. According to Anstey et al., factors such as cognition, vision, and other physical functions determine an individual's driving capacity, but it's impossible to assess these characteristics fully [44]. However, according to the data provided by Streetsblog NYC, the number of speeding tickets captured by city cameras in residential areas and school zones went up by $57 \%$ during the first 10 weekdays after New York started the "pause" [45]. In addition, six cyclists and drivers died in NYC between March 2 and April 9, 2020, the highest number of deaths for the time period since the city's Vision Zero initiative started five years ago [42]. Other sources reported as much as a 200 percent rise in speeding since the lockdown began [46].

Our dataset contained information from all police-reported motor vehicle collisions in NYC during the following two time periods:

(1) January 15 to March 15, 2020, defined as the pre-lockdown period, and

(2) March 16 to May 15, 2020, defined as the lockdown period. 


\section{Cureus}

Each row represents a car accident and outlines each event's characteristics. NYC Open Data Portal (https://opendata.cityofnewyork.us) provided the statistical data on motor vehicle collisions. All numbers and statistical information included in the analysis have been updated and grouped by boroughs. Overall, it is evident that 29,335 car crashes were recorded before the COVID-19 lockdown, which was $75.1 \%$ of the total car crashes, but just 9,719 car crashes were observed during the lockdown period, or only $24.9 \%$ of total car crashes.

Table 3 and Table 4 represent the number and percentage of injuries in car crashes before and during the COVID-19 lockdown period. During the pre-lockdown period, $17 \%$ of car accidents resulted in injuries to one person. Accidents with two injuries totaled 929 (3.2\%). Accidents with three injuries totaled 327 (1.1\%). Accidents with four injuries totaled 102 (0.3\%). Accidents with five or more injuries comprised $0.1 \%$ of the total. $78 \%$ of crashes during the pre-lockdown period resulted in no injuries.

\begin{tabular}{|c|c|c|c|}
\hline Number of Injuries & Frequency & Percentage & Valid Percentage \\
\hline 1 & 5,009 & 17.1 & 78.0 \\
\hline 2 & 929 & 3.2 & 14.5 \\
\hline 3 & 327 & 1.1 & 5.1 \\
\hline 4 & 102 & .3 & 1.6 \\
\hline 5 & 34 & .1 & .5 \\
\hline 6 & 9 & .0 & .1 \\
\hline 7 & 3 & .0 & .0 \\
\hline 8 & 5 & .0 & .1 \\
\hline 9 & 3 & .0 & .0 \\
\hline 10 & 1 & .0 & .0 \\
\hline Total & 6,422 & 21.9 & 100.0 \\
\hline 0 & 22,913 & 78.1 & \\
\hline
\end{tabular}

TABLE 3: Number of injuries during the pre-lockdown period

\begin{tabular}{|c|c|c|c|}
\hline Number of Injuries & Frequency & Percentage & Valid Percentage \\
\hline 1 & 1,772 & 18.2 & 78.8 \\
\hline 2 & 340 & 3.5 & 15.1 \\
\hline 3 & 93 & 1 & 4.1 \\
\hline 4 & 32 & 0.3 & 1.4 \\
\hline 5 & 10 & 0.1 & 0.4 \\
\hline 7 & 3 & 0 & 0.1 \\
\hline Total & 2,250 & 23.2 & 100 \\
\hline 0 & 7,469 & 76.8 & \\
\hline
\end{tabular}

TABLE 4: Number of injuries during the lockdown period

During the lockdown period, accidents with one injury totaled 18\%. Accidents with two injuries totaled 340 (3.5\%). Accidents with three injuries totaled 93 (1.0\%). Accidents with four injuries totaled 32 (0.3\%). Accidents with five injuries comprised $0.1 \%$ of the total. $77 \%$ of car accidents during the COVID-19 


\section{Cureus}

lockdown period resulted in no injuries.

Figure 1 provides car-crash times during the pre-lockdown period, indicating that crashes peaked between 7:08 and 19:38. Similarly, crashes during the COVID-19 lockdown period peaked between 7:27 and 19:46, as shown in Figure 1. Thus, even though the number of car crashes decreased during the COVID-19 lockdown period, the time of day when they occurred most frequently remained almost the same as before the lockdown.
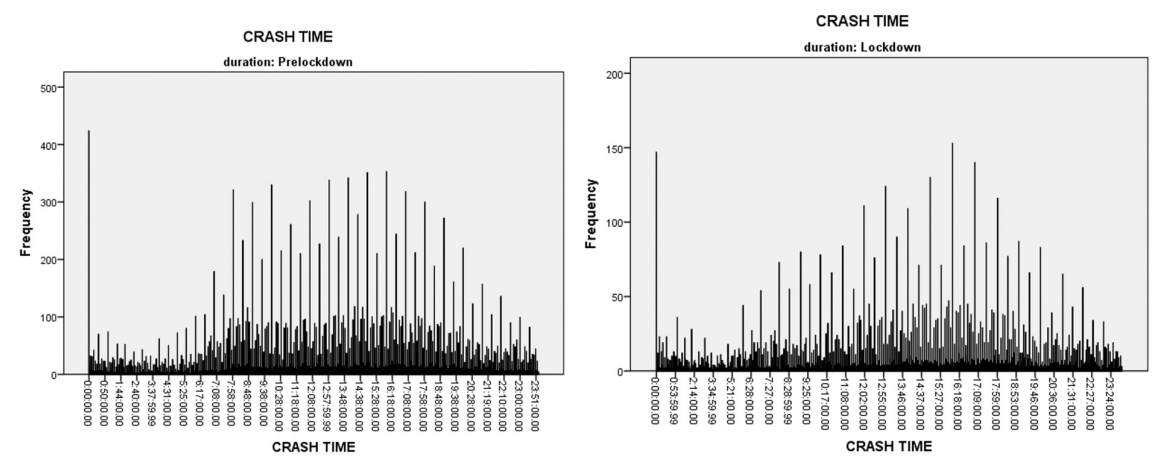

FIGURE 1: Times of car crashes during the pre-lockdown vs. lockdown period

Table 5 provides an overview of the number of injuries in each borough before and during the COVID-19 lockdown period. As for car accidents in which only one injury was reported, $21 \%$ occurred in Brooklyn, $20 \%$ in Queens, $12 \%$ in the Bronx, 11\% in Manhattan and 2\% in Staten Island before the lockdown was implemented. The proportions were similar for crashes in which two people were injured, with $22 \%$ in Brooklyn and 19\% in Queens, followed by the Bronx (9\%), Manhattan (6\%), and Staten Island (2\%). Brooklyn, Queens, and the Bronx remained the deadliest areas, with a higher percentage of car crashes with three, four, and five injuries each. 


\section{Cureus}

\begin{tabular}{|c|c|c|c|c|c|c|c|c|c|c|c|}
\hline \multicolumn{4}{|c|}{ lockdown period } & \multicolumn{8}{|c|}{ Number of people injured in New York City boroughs during the pre- } \\
\hline \multirow{2}{*}{ Borough } & & & & & & \multicolumn{5}{|c|}{ People Injured } & \multirow[t]{2}{*}{ Total } \\
\hline & 1 & 2 & 3 & 4 & 5 & 6 & 7 & 8 & 9 & 10 & \\
\hline \multirow{2}{*}{ Not defined } & 1,735 & 391 & 140 & 53 & 14 & 2 & 3 & 3 & 2 & 1 & 2,344 \\
\hline & $35 \%$ & $42 \%$ & $43 \%$ & $52 \%$ & $41 \%$ & $22 \%$ & $100 \%$ & $60 \%$ & $67 \%$ & $100 \%$ & $36 \%$ \\
\hline \multirow{2}{*}{ Bronx } & 594 & 83 & 48 & 10 & 3 & 3 & 0 & 0 & 1 & 0 & 742 \\
\hline & $12 \%$ & $9 \%$ & $15 \%$ & $10 \%$ & $9 \%$ & $33 \%$ & $0 . \%$ & $0 \%$ & $33 \%$ & $0 \%$ & $11 \%$ \\
\hline \multirow{2}{*}{ Brooklyn } & 1,055 & 201 & 70 & 14 & 10 & 2 & 0 & 2 & 0 & 0 & 1,354 \\
\hline & $21 \%$ & $22 \%$ & $21 \%$ & $14 \%$ & $29 \%$ & $22 \%$ & $0 . \%$ & $40 \%$ & $0 \%$ & $0 \%$ & $21 \%$ \\
\hline \multirow{2}{*}{ Manhattan } & 539 & 59 & 10 & 4 & 1 & 0 & 0 & 0 & 0 & 0 & 613 \\
\hline & $11 \%$ & $6 \%$ & $3 \%$ & $4 \%$ & $3 \%$ & $0 \%$ & $0 . \%$ & $0 \%$ & $0 \%$ & $0 \%$ & $10 \%$ \\
\hline \multirow{2}{*}{ Queens } & 982 & 178 & 48 & 16 & 6 & 2 & 0 & 0 & 0 & 0 & 1,232 \\
\hline & $20 \%$ & $19 \%$ & $15 \%$ & $16 \%$ & $18 \%$ & $22 \%$ & $0 . \%$ & $0 \%$ & $0 \%$ & $0 \%$ & $19 \%$ \\
\hline \multirow{2}{*}{ Staten Island } & 104 & 17 & 11 & 5 & 0 & 0 & 0 & 0 & 0 & 0 & 137 \\
\hline & $2 \%$ & $2 \%$ & $3 \%$ & $5 \%$ & $0 \%$ & $0 \%$ & $0 . \%$ & $0 \%$ & $0 \%$ & $0 \%$ & $2 \%$ \\
\hline \multirow[t]{2}{*}{ Total } & 5,009 & 929 & 327 & 102 & 34 & 9 & 3 & 5 & 3 & 1 & 6,422 \\
\hline & $100 \%$ & $100 \%$ & $100 \%$ & $100 \%$ & $100 \%$ & $100 \%$ & $100 \%$ & $100 \%$ & $100 \%$ & $100 \%$ & $100 \%$ \\
\hline
\end{tabular}

TABLE 5: Number of people injured in New York City boroughs during the pre-lockdown period

During the COVID-19 lockdown period, most car crashes with one injury occurred in Brooklyn (23\%), followed by Queens (14\%) and the Bronx (12\%), with very few recorded in Manhattan (7\%) and Staten Island (3\%). The proportions were similar when two injuries were reported, with $22 \%$ in Brooklyn, $17 \%$ in Queens, and $8 \%$ in the Bronx. Car accidents with three and four injuries were higher in Brooklyn and the Bronx, followed by Queens, Manhattan, and Staten Island. See Table 6 for details. 


\begin{tabular}{|c|c|c|c|c|c|c|c|c|c|c|c|}
\hline \multirow{2}{*}{ Borough } & \multirow[b]{2}{*}{1} & \multirow[b]{2}{*}{2} & \multirow[b]{2}{*}{3} & \multicolumn{7}{|c|}{ Persons Injured } & \multirow[t]{2}{*}{ Total } \\
\hline & & & & 4 & 5 & 6 & 7 & 8 & 9 & 10 & \\
\hline \multirow{2}{*}{ Not Defined } & 718 & 148 & 48 & 15 & 7 & & 2 & & & & 938 \\
\hline & $45 \%$ & $44 \%$ & $52 \%$ & $47 \%$ & $70 \%$ & & $67 \%$ & & & & $41 \%$ \\
\hline \multirow{2}{*}{ Bronx } & 209 & 28 & 11 & 3 & 1 & & 0 & & & & 252 \\
\hline & $12 \%$ & $8 \%$ & $12 \%$ & $9 \%$ & $10 \%$ & & $0 \%$ & & & & $11 \%$ \\
\hline \multirow{2}{*}{ Brooklyn } & 413 & 74 & 19 & 7 & 1 & & 1 & & & & 515 \\
\hline & $23 \%$ & $22 \%$ & $20 \%$ & $22 \%$ & $10 \%$ & & $33 \%$ & & & & $23 \%$ \\
\hline \multirow{2}{*}{ Manhattan } & 132 & 24 & 4 & 2 & 0 & & 0 & & & & 162 \\
\hline & $7 \%$ & $7 \%$ & $4 \%$ & $6 \%$ & $0 \%$ & & $0 \%$ & & & & $7 \%$ \\
\hline \multirow{2}{*}{ Queens } & 255 & 56 & 10 & 5 & 0 & & 0 & & & & 326 \\
\hline & $14 \%$ & $17 \%$ & $11 \%$ & $16 \%$ & $0 \%$ & & $0 \%$ & & & & $15 \%$ \\
\hline \multirow{2}{*}{ Staten island } & 45 & 10 & 1 & 0 & 1 & & 0 & & & & 57 \\
\hline & $3 \%$ & $3 \%$ & $1 \%$ & $0 \%$ & $10 \%$ & & $0 \%$ & & & & $3 \%$ \\
\hline \multirow[t]{2}{*}{ Total } & 1,772 & 340 & 93 & 32 & 10 & & 3 & & & & 2,250 \\
\hline & $100 \%$ & $100 \%$ & $100 \%$ & $100 \%$ & $100 \%$ & & $100 \%$ & & & & $100 \%$ \\
\hline
\end{tabular}

TABLE 6: Number of people injured in New York City boroughs during the lockdown period

\section{Effect on emergency department visits}

According to the National Syndromic Surveillance Program (NSSP), this pandemic affected emergency department (ED) visits nationwide. According to the CDC, ED visits declined $42 \%$ during the first month of the pandemic, from a mean of 2.1 million per week (March 31 to April 27, 2019) to 1.2 million (March 29 to April 25, 2020) [47]. These changes have been observed in individuals $\leqslant 14$ years and female patients. Interestingly, Northeast hospital emergency rooms started seeing a sharp decrease in people coming in with non-COVID-19 issues in early April, a characteristic sign of the public health crisis. Visits to the ER were down $26 \%$ in the last week of May compared with a year earlier.

Based on U.S. Department of Health and Human Services data, the largest decline in ED visits was recorded in the Northeast (Region 1, 49\%) and in the region that includes New Jersey and New York (Region 2, 48\%) [47]. Trauma injuries also were affected during the quarantine, as the number of traffic injuries and outdoor traumas showed a significant decrease during the early stages of the pandemic, then began to increase on February 17. While data on New York and New Jersey remain unavailable, the volume of people entering ERs with various traumas was lower than before the virus.

From March 11 to May 2, 2020, the New York City Department of Health and Mental Hygiene (DOHMH) reported 32,107 deaths, with $24,172(95 \% \mathrm{CI}=22,980-25,364)$ found to be in excess of the seasonal expected baseline. Included in the 24,172 deaths were 13,831 (57\%) laboratory-confirmed COVID-19-associated deaths and 5,048 (21\%) probable COVID-19-related deaths According to the same data set, 5,293 (22\%) excess deaths have not been identified as either laboratory-confirmed or presumed COVID-19-related deaths. It has been concluded that these deaths might have been attributable directly or indirectly to the pandemic and lockdown, but the percentages of deaths from trauma-related impacts from the lockdown remain unknown [48].

According to data shared with CNBC, emergency room visits were down by about 50\% across New York City Health + Hospital locations. The number of injuries across the city has fallen, as most individuals stayed home under the lockdown order. Moreover, patient visits dropped in the private sector as well, but an unusual uptick in patients who normally seek treatment at hospitals (including various injuries) was recorded [49]. There was also a significant decrease in patients requiring emergency help for conditions like heart attacks and asthma exacerbation. Table 7 provides additional data on the differences in mean weekly numbers of emergency department (ED) visits. 


\section{Cureus}

\section{Diagnostic category}

Change in mean number of weekly ED visits*

$-33,709$

Sprains and strains, initial encounter

Superficial injuries, contusions, initial encounter

Other unspecified injuries
$-30,918$

$-25,974$
Prevalence ratio $(95 \% \mathrm{Cl})$

$0.61(0.61-0.62)$

$0.85(0.84-0.85)$

$0.84(0.83-0.84)$

TABLE 7: Differences in weekly numbers of emergency department (ED) visits for trauma-related diagnostic categories - National Syndromic Surveillance Program, United States, March 31 to April 27, 2019 (comparison period) and March 29 to April 25, 2020 (early pandemic period) [48]

\section{Cumulative results and suggestions}

Although road safety has increased greatly over the past years in all NYC boroughs - attributable to improvements in road systems, new laws, and public health and prevention campaigns - enforcement of these laws to improve compliance with suggested regulations has helped reduce the prevalence of car accidents significantly.

Research suggests that young male drivers are most likely to violate basic driving rules and perpetrate road rage. Additionally, the New York State Department of Health reported that young males are almost twice as likely to be hospitalized with a TBI [36]. Although factors such as crowded roads usually boost anger behind the wheel, it has been noted that "stay home" restrictions have not changed this behavior. As previously noted, many professionals suggested that psychological factors such as life stressors may lead to displaced anger [50]. We believe that pandemic-associated stress could lead to similar changes in drivers' behavior.

The evidence indicates that when a considerable percentage of cars is restricted from driving, this restriction reduces standard traveling time by up to $30 \%$. Moreover, the policy may shape and improve driving behavior during the regulated period without worsening it during the non-regulated period. The driving restriction should help boost the use of public transit and taxi and/or car-sharing services, but several studies confirmed that such usage would not be statistically insignificant.

To improve traffic conditions further and reduce the number of traumatic outcomes, NYC may impose rules barring cars from the busiest areas based on license plate numbers to control traffic congestion. The government also should set the total number of car licenses that can be issued per year at the city level. We believe that these preventive measures may limit the growing number of car owners in NYC. While all these measures may be effective in theory, we cannot estimate whether this policy would be effective enough in the short run to justify implementation in NYC.

During our analysis, it was noted that most similar extant research focused on crash-causing behaviors instead of everyday driving behaviors. Moreover, no research has focused on driving errors that typical car owners and riders make on a daily basis. This means that we could not fully assess driving behavior due to a lack of any standards. It is imperative to determine what kind of driving "errors" New Yorkers have made and whether these issues have been dangerous or simply "normal habits" that most city drivers make at some point in their lives. It remains unclear how to score different types of behavior or "driving errors." It makes on-road tests' reliability questionable, which, in turn, suggests that these tests may have low validity. We believe that future research should focus on the observation and assessment of citizens' actual driving behavior using on-road assessment strategies. This approach would help distinguish between safe and unsafe driving, which is critical to New Yorkers' safety.

\section{Conclusions}

Public health initiatives coordinated across the city and communities could help to prevent the occurrence of TBIs. However, current data do not provide enough details needed to fully understand the epidemiology and potential outcomes of TBI prevention programs. Nevertheless, overall decreases in TBI-related hospitalizations and deaths due to MVA indicate significant progress of TBI-prevention efforts. Moreover, it has been suggested that the quarantine and transportation restrictions introduced in New York City decreased the incidence of MVA - related injuries in several areas. To improve traffic conditions and indirectly affect the incidence of TBI cases, we concluded that NYC should implement certain measures such as a driving restriction policy. The rates of TBI-related deaths due to intentional self-harm and/or falls remain high, which reflects the increase in suicide rates across the United States, suggesting the need for expansion of comprehensive and well-coordinated TBI- prevention efforts, but in different directions.

\section{Appendices}




\section{Cureus}

\begin{tabular}{|c|c|c|c|c|c|c|c|c|c|}
\hline \multicolumn{10}{|c|}{ March 2020 Motor-Vehicle Deaths and Changes United States, Three Months, 2017 to $2020^{\star}$} \\
\hline \multirow{3}{*}{ Month } & \multicolumn{4}{|c|}{ Number of Deaths } & \multicolumn{5}{|c|}{ Percent Changes } \\
\hline & \multirow{2}{*}{2017} & \multirow{2}{*}{2018} & \multirow{2}{*}{2019} & \multirow{2}{*}{2020} & \multicolumn{3}{|c|}{ Corresponding Month } & \multicolumn{2}{|c|}{ Four Month Moving Average + } \\
\hline & & & & & 2018 to 2020 & 2018 to 2019 & 2019 to 2020 & 20118 to 2019 & 2019 to 2020 \\
\hline January & 3,034 & 3,010 & 2,830 & 2,900 & $-4 \%$ & & $2 \%$ & & $<0.5 \%$ \\
\hline February & 2,748 & 2,734 & 2,590 & 2,870 & $5 \%$ & & $11 \%$ & & $4 \%$ \\
\hline March & 3,164 & 3,015 & 2,910 & 2,690 & $-11 \%$ & & $-8 \%$ & & $1 \%$ \\
\hline 3 Months & 8,946 & 8,759 & 8,330 & 8,460 & $-3 \%$ & & $2 \%$ & & \\
\hline April & 3,238 & 2,979 & 3,040 & & & $2 \%$ & & $-3 \%$ & \\
\hline May & 3,416 & 3,443 & 3,410 & & & $-1 \%$ & & $-2 \%$ & \\
\hline June & 3,492 & 3,514 & 3,420 & & & $-3 \%$ & & $-1 \%$ & \\
\hline July & 3,730 & 3,552 & 3,530 & & & $-1 \%$ & & $-1 \%$ & \\
\hline August & 3,409 & 3,490 & 3,570 & & & $2 \%$ & & $<0.5 \%$ & \\
\hline September & 3,572 & 3,579 & 3,520 & & & $-2 \%$ & & $-1 \%$ & \\
\hline October & 3,629 & 3,657 & 3,430 & & & $-6 \%$ & & $-2 \%$ & \\
\hline November & 3,408 & 3,250 & 3,340 & & & $3 \%$ & & $-1 \%$ & \\
\hline December & 3,391 & 3,181 & 3,210 & & & $1 \%$ & & $-1 \%$ & \\
\hline TOTAL & 40,231 & 39,404 & 38,800 & 38,930 & \# & & & & \\
\hline $\begin{array}{l}\text { traffic and } n \\
\text { days. The } 2 \\
\text { estimates. * } \\
\text { between the } \\
\text { be affected } \\
\text { for the 12-m }\end{array}$ & $\begin{array}{l}\text { nal Satety } \\
\text { ontraffic d } \\
17 \text { and } 20 \\
\text { atest upd }\end{array}$ & $\begin{array}{l}\text { Councll } \\
\text { eaths the } \\
18 \text { data } \\
\text { ates: } 20\end{array}$ & $\begin{array}{l}\text { gures ar } \\
\text { occur w } \\
\text { re from } t \\
--12 / 14\end{array}$ & $\begin{array}{l}\text { not com } \\
\text { thin a ye } \\
\text { e Nation } \\
18 ; 2018-\end{array}$ & $\begin{array}{l}\text { parable to Natic } \\
\text { ar of the accider } \\
\text { al Center for He } \\
-2 / 13 / 19 ; 2019\end{array}$ & $\begin{array}{l}\text { thal while NHTSA } \\
\text { alth Statistics. A } \\
2 / 17 / 20 \text {. +Four- }\end{array}$ & $\begin{array}{l}\text { counts only traf } \\
\text { cother figures a } \\
\text { Month Moving A }\end{array}$ & $\begin{array}{l}\text { nistration figures } \\
\text { ic deaths that oc } \\
\text { e National Safety } \\
\text { verage is based }\end{array}$ & $\begin{array}{l}\text { ur within } 30 \\
\text { Council } \\
\text { changes } \\
\text { hanges that may } \\
\text { tions. \#Deaths }\end{array}$ \\
\hline
\end{tabular}

TABLE 8: Motor-Vehicle Deaths and Changes United States, Three Months, 2017 to 2020

\begin{tabular}{|c|c|c|c|c|c|c|}
\hline \multicolumn{7}{|c|}{ State motor-vehicle deaths and percent changes } \\
\hline \multirow{2}{*}{ State } & \multirow{2}{*}{ Number of Months Reported } & \multicolumn{3}{|c|}{ Deaths Identical Periods } & \multicolumn{2}{|l|}{ Percent Changes } \\
\hline & & 2020 & 2019 & 2018 & 2019 to 2020 & 2018 to 2020 \\
\hline TOTAL U.S. & 3 & 8,460 & 8,330 & 8,759 & $2 \%$ & $-3 \%$ \\
\hline Alabama & 3 & 197 & 190 & 229 & $4 \%$ & $-14 \%$ \\
\hline Alaska & 3 & 13 & 17 & 13 & $-24 \%$ & $0 \%$ \\
\hline Arizona & 3 & 232 & 241 & 265 & $-4 \%$ & $-12 \%$ \\
\hline Arkansas & 3 & 114 & 98 & 87 & $16 \%$ & $31 \%$ \\
\hline California & 3 & 685 & 633 & 542 & $8 \%$ & $26 \%$ \\
\hline Colorado & 3 & 101 & 95 & 120 & $6 \%$ & $-16 \%$ \\
\hline Connecticut & 3 & 68 & 48 & 52 & $42 \%$ & $31 \%$ \\
\hline Delaware & 3 & 23 & 18 & 21 & $28 \%$ & $10 \%$ \\
\hline DC & 3 & 7 & 3 & 7 & $133 \%$ & $0 \%$ \\
\hline
\end{tabular}




\section{Cureus}

\begin{tabular}{|c|c|c|c|c|c|c|c|c|}
\hline Florida & 3 & & & 894 & 882 & 866 & $1 \%$ & $3 \%$ \\
\hline Georgia & 3 & & & 366 & 354 & 326 & $3 \%$ & $12 \%$ \\
\hline Hawaii & 3 & & & 21 & 31 & 25 & $-32 \%$ & $-16 \%$ \\
\hline Idaho & 3 & & & 28 & 39 & 29 & $-28 \%$ & $-3 \%$ \\
\hline Illinois & 3 & & & 188 & 170 & 239 & $11 \%$ & $-21 \%$ \\
\hline Indiana & 3 & & & 146 & 154 & 189 & $-5 \%$ & $-23 \%$ \\
\hline lowa & 3 & & & 54 & 62 & 61 & $-13 \%$ & $-11 \%$ \\
\hline Kansas & 3 & & & 96 & 93 & 88 & $3 \%$ & $9 \%$ \\
\hline Kentucky & 3 & & & 138 & 149 & 152 & $-7 \%$ & $-9 \%$ \\
\hline Louisiana & 3 & & & 170 & 138 & 163 & $23 \%$ & $4 \%$ \\
\hline Maine & 3 & & & 28 & 32 & 12 & $-13 \%$ & $133 \%$ \\
\hline Maryland & 3 & & & 90 & 104 & 89 & $-13 \%$ & $1 \%$ \\
\hline Massachusetts & 3 & & & 69 & 73 & 81 & $-5 \%$ & $-15 \%$ \\
\hline Michigan & 3 & & & 174 & 198 & 177 & $-12 \%$ & $-2 \%$ \\
\hline Minnesota & 3 & & & 68 & 67 & 57 & $1 \%$ & $19 \%$ \\
\hline Mississippi & 3 & & & 125 & 127 & 135 & $-2 \%$ & $-7 \%$ \\
\hline Missouri & & 3 & 175 & & 163 & 184 & $7 \%$ & $-5 \%$ \\
\hline Montana & & 3 & 27 & & 20 & 21 & $35 \%$ & $29 \%$ \\
\hline Nebraska & & 3 & 41 & & 44 & 49 & $-7 \%$ & $-16 \%$ \\
\hline Nevada & & 3 & 66 & & 60 & 73 & $10 \%$ & $-10 \%$ \\
\hline New Hampshire & & 3 & 27 & & 14 & 21 & $93 \%$ & $29 \%$ \\
\hline New Jersey & & 3 & 123 & & 119 & 119 & $3 \%$ & $3 \%$ \\
\hline New Mexico & & 3 & 101 & & 103 & 77 & $-2 \%$ & $31 \%$ \\
\hline New York & & 3 & 149 & & 127 & 148 & $17 \%$ & $1 \%$ \\
\hline North Carolina & & 3 & 314 & & 285 & 325 & $10 \%$ & $-3 \%$ \\
\hline North Dakota & & 3 & 7 & & 17 & 13 & $-59 \%$ & $-46 \%$ \\
\hline Ohio & & 3 & 231 & & 240 & 224 & $-4 \%$ & $3 \%$ \\
\hline Oklahoma & & 3 & 131 & & 120 & 146 & $9 \%$ & $-10 \%$ \\
\hline Oregon & & 3 & 75 & & 99 & 94 & $-24 \%$ & $-20 \%$ \\
\hline Pennsylvania & & 3 & 222 & & 233 & 284 & $-5 \%$ & $-22 \%$ \\
\hline Rhode Island & & 3 & 12 & & 13 & 11 & $-8 \%$ & $9 \%$ \\
\hline South Carolina & & 3 & 186 & & 211 & 189 & $-12 \%$ & $-2 \%$ \\
\hline South Dakota & & 3 & 18 & & 13 & 24 & $38 \%$ & $-25 \%$ \\
\hline Tennessee & & 3 & 240 & & 227 & 209 & $6 \%$ & $15 \%$ \\
\hline Texas & & 3 & 861 & & 813 & 893 & $6 \%$ & $-4 \%$ \\
\hline Utah & & 3 & 56 & & 48 & 54 & $17 \%$ & $4 \%$ \\
\hline Vermont & & 3 & 6 & & 3 & 7 & $100 \%$ & $-14 \%$ \\
\hline Virginia & & 3 & 189 & & 183 & 182 & $3 \%$ & $4 \%$ \\
\hline Washington & & 3 & 96 & & 119 & 100 & $-19 \%$ & $-4 \%$ \\
\hline
\end{tabular}




\section{Cureus}

$\begin{array}{lllllll}\text { West Virginia } & 3 & 56 & 55 & 57 & 2 \% & -2 \% \\ \text { Wisconsin } & 3 & 84 & 99 & 130 & -15 \% & -35 \% \\ \text { Wyoming } & 3 & 7 & 35 & 20 & -80 \% & -65 \%\end{array}$

NOTE: Deaths are reported by state traffic authorities. All figures are preliminary. To ensure proper comparisons, 2018 and $2019 f i g u r e s$ are preliminary figures covering the same reporting period as those for 2020 . The total for 2018 is from the National Center for Health Statistics.

TABLE 9: State motor-vehicle deaths and percent changes

Preliminary monthly fatality totals reported by states*, 2019-2020

\begin{tabular}{|c|c|c|c|c|}
\hline Year & State & January & February & March \\
\hline 2020 & Alaska & 4 & 6 & 3 \\
\hline 2020 & Alabama & 56 & 70 & 71 \\
\hline 2020 & Arkansas & 39 & 36 & 39 \\
\hline 2020 & Arizona & 76 & 105 & 51 \\
\hline 2020 & California & 278 & 244 & 163 \\
\hline 2020 & Colorado & 32 & 35 & 34 \\
\hline 2020 & Connecticut & 24 & 23 & 21 \\
\hline 2020 & Delaware & 10 & 8 & 5 \\
\hline 2020 & Dist. of Columbia & 5 & 2 & 0 \\
\hline 2020 & Florida & 318 & 275 & 301 \\
\hline 2020 & Georgia & 102 & 126 & 138 \\
\hline 2020 & Hawaii & 12 & 5 & 4 \\
\hline 2020 & lowa & 24 & 17 & 13 \\
\hline 2020 & Idaho & 6 & 14 & 8 \\
\hline 2020 & Illinois & 76 & 65 & 47 \\
\hline 2020 & Indiana & 47 & 41 & 58 \\
\hline 2020 & Kansas & 30 & 35 & 31 \\
\hline 2020 & Kentucky & 45 & 42 & 51 \\
\hline 2020 & Louisiana & 58 & 50 & 62 \\
\hline 2020 & Massachusetts & 21 & 20 & 28 \\
\hline 2020 & Maryland & 20 & 31 & 39 \\
\hline 2020 & Maine & 16 & 6 & 6 \\
\hline 2020 & Michigan & 64 & 62 & 48 \\
\hline 2020 & Minnesota & 18 & 22 & 28 \\
\hline 2020 & Missouri & 50 & 73 & 52 \\
\hline 2020 & Mississippi & 37 & 51 & 37 \\
\hline 2020 & Montana & 10 & 4 & 13 \\
\hline 2020 & North Carolina & 117 & 88 & 109 \\
\hline 2020 & North Dakota & 2 & 1 & 4 \\
\hline
\end{tabular}




\section{Cureus}

\begin{tabular}{|c|c|c|c|c|}
\hline 2020 & Nebraska & 14 & 17 & 10 \\
\hline 2020 & New Hampshire & 10 & 8 & 9 \\
\hline 2020 & New Jersey & 46 & 41 & 36 \\
\hline 2020 & New Mexico & 41 & 28 & 32 \\
\hline 2020 & Nevada & 24 & 25 & 17 \\
\hline 2020 & New York & 71 & 51 & 27 \\
\hline 2020 & Ohio & 77 & 69 & 85 \\
\hline 2020 & Oklahoma & 42 & 45 & 44 \\
\hline 2020 & Oregon & 35 & 22 & 18 \\
\hline 2020 & Pennsylvania & 90 & 60 & 72 \\
\hline 2020 & Rhode Island & 4 & 3 & 5 \\
\hline 2020 & South Carolina & 62 & 65 & 59 \\
\hline 2020 & South Dakota & 5 & 10 & 3 \\
\hline 2020 & Tennessee & 74 & 89 & 77 \\
\hline 2020 & Texas & 307 & 304 & 250 \\
\hline 2020 & Utah & 15 & 19 & 22 \\
\hline 2020 & Virginia & 72 & 62 & 55 \\
\hline 2020 & Vermont & 3 & 1 & 2 \\
\hline 2020 & Washington & 38 & 28 & 30 \\
\hline 2020 & Wisconsin & 25 & 30 & 29 \\
\hline 2020 & West Virginia & 19 & 23 & 14 \\
\hline 2020 & Wyoming & 2 & 1 & 4 \\
\hline 2019 & Alaska & 7 & 4 & 6 \\
\hline 2019 & Alabama & 74 & 43 & 73 \\
\hline 2019 & Arkansas & 38 & 25 & 35 \\
\hline 2019 & Arizona & 84 & 75 & 82 \\
\hline 2019 & California & 274 & 190 & 169 \\
\hline 2019 & Colorado & 32 & 24 & 39 \\
\hline 2019 & Connecticut & 21 & 11 & 16 \\
\hline 2019 & Delaware & 5 & 4 & 9 \\
\hline 2019 & Dist. of Columbia & 0 & 2 & 1 \\
\hline 2019 & Florida & 254 & 294 & 334 \\
\hline 2019 & Georgia & 126 & 96 & 132 \\
\hline 2019 & Hawaii & 14 & 10 & 7 \\
\hline 2019 & lowa & 21 & 20 & 21 \\
\hline 2019 & Idaho & 8 & 21 & 10 \\
\hline 2019 & Illinois & 52 & 39 & 79 \\
\hline 2019 & Indiana & 42 & 71 & 41 \\
\hline 2019 & Kansas & 33 & 21 & 39 \\
\hline
\end{tabular}




\section{Cureus}

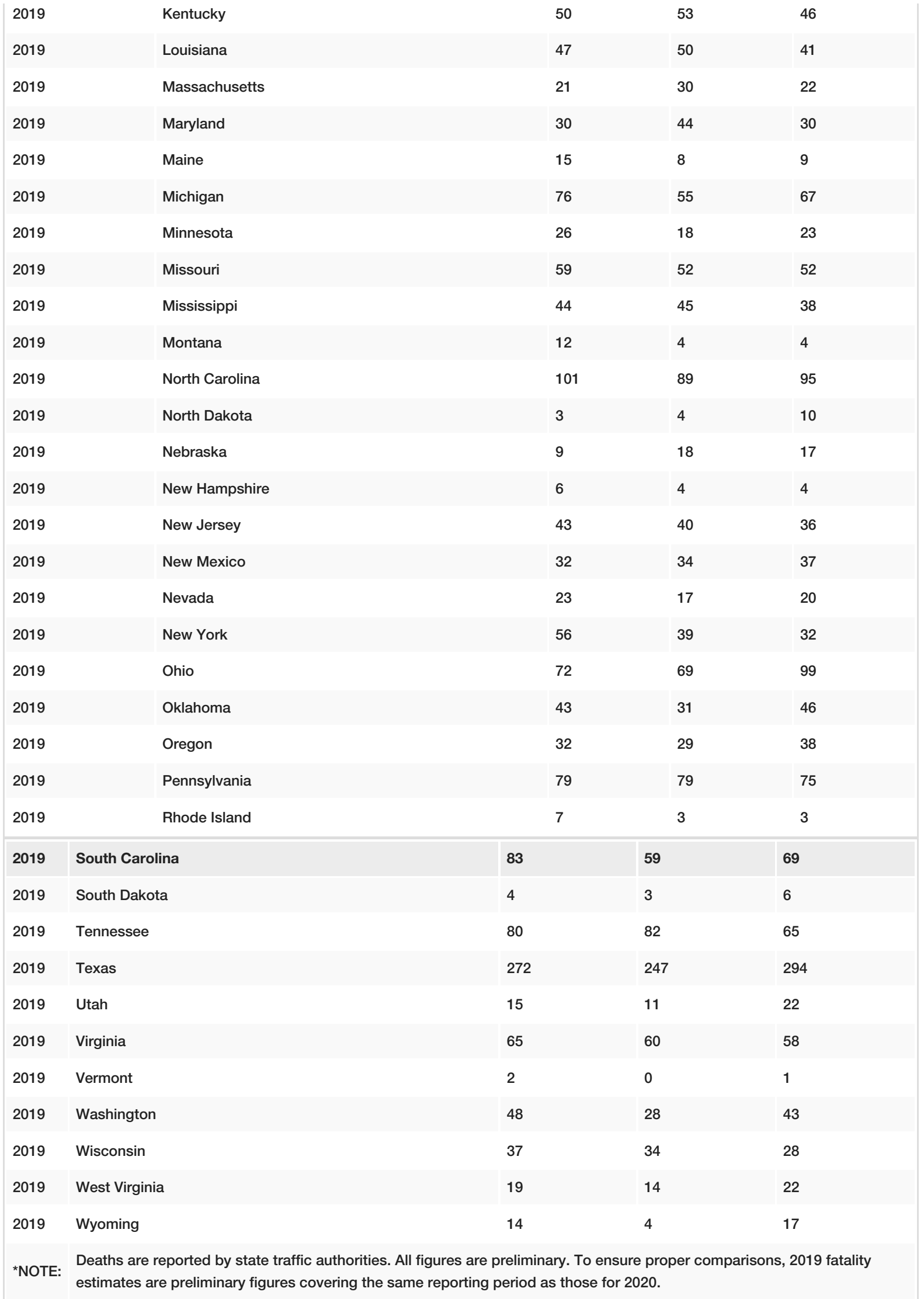

TABLE 10: Preliminary monthly fatality totals reported by states*, 2019-2020 


\section{Disclosures}

Conflicts of interest: In compliance with the ICMJE uniform disclosure form, all authors declare the following: Payment/services info: All authors have declared that no financial support was received from any organization for the submitted work. Financial relationships: All authors have declared that they have no financial relationships at present or within the previous three years with any organizations that might have an interest in the submitted work. Other relationships: All authors have declared that there are no other relationships or activities that could appear to have influenced the submitted work.

\section{References}

1. Maas AIR, Menon DK, Adelson P, et al.: Traumatic brain injury: integrated approaches to improve prevention, clinical care, and research. Lancet Neurol. 2017., 16:987-1048. 10.1016/S1474-4422(17)30371-X

2. Fu TS, Jing R, Fu WW, Cusimano MD: Epidemiological trends of traumatic brain injury identified in the emergency department in a publicly-insured population 2002-2010. PLoS One. 2016, 11:e0145469. 10.1371/journal.pone.0145469

3. Durić A, Omerbegović M, Ajanović M, Mahić Z, Alić M, Vanis-Vatrenjak S: Prevention of secondary brain injury. Med Arh. 2006, 60:120-123.

4. Dhawan P, Rose A, Krassioukov A, Miller WC: Early interventions for mild traumatic brain injury: reflections on experience. BCMJ. 2006, 9:442-446.

5. Wilson MH: Traumatic brain injury: an underappreciated public health issue . Lancet Public Health. 2016, 1:e44. 10.1016/S2468-2667(16)30022-6

6. Rehabilitation of Persons With Traumatic Brain Injury. NIH Consens Statement. 1998, 6:1-41.

7. Bruns J, Hauser WA: The epidemiology of traumatic brain injury: a review . Epilepsia. 2003, 44:2-10. 10.1046/j.1528-1157.44.s10.3.x

8. Stallones L, Gibbs-Long J, Gabella B, Kakefuda I: Community readiness and prevention of traumatic brain injury. Brain Injury. 2008., 22:555-564. 10.1080/02699050802132487

9. Dams-O’Connor K, Cantor JB, Brown M: Screening for traumatic brain injury: findings and public health implications. J Head Trauma Rehabil. 2014, 29:479-489. 10.1097/htr.0000000000000099

10. David W, Kellermann A, McGuire LC, Chen B, Popovic T: CDC grand rounds: Reducing severe traumatic brain injury in the United States. Morbidity Mortality Wkly Rep. 2013, 62:549-552.

11. Dewan MC, Rattani A, Gupta S, Baticulon RE, Hung Y-C, Punchak M: Estimating the global incidence of traumatic brain injury. J Neurosurgery. 2018, 130:1039-1408. 10.3171/2017.10.JNS17352

12. Bigler ED: Neuropathology of Mild Traumatic Brain Injury: Correlation to Neurocognitive and Neurobehavioral Findings. Frontiers in Neuroengineering. Chapter 31. 2015.

13. Galgano M, Toshkezi G, Qiu X, Russell T, Chin L, Zhao L-R: Traumatic brain injury: current treatment strategies and future endeavors. Cell Transpl. 2017, 26:1118-1130. 10.1177/0963689717714102

14. Dismuke CE, Walker RJ, Egede LE: Utilization and cost of health services in individuals with traumatic brain injury. Global J Health Sci. 2015, 7:156-169. 10.5539/gjhs.v7n6p156

15. Whiteneck G, Cuthbert J, Corrigan J, Bogner J: Prevalence of self-reported lifetime history of traumatic brain injury and associated disability: a statewide population-based survey. J Head Trauma Rehabil. 2016, 31:e55e62. 10.1097/HTR.0000000000000140

16. McAllister TW: Neurobiological consequences of traumatic brain injury . Dialogues Clin Neurosci. 2011, 13:287-300.

17. Manchester K, Corrigan JD, Singichetti B: Current health status and history of traumatic brain injury among Ohio adults. Injury Prevention. 2020, 26:129-137. 10.1136/injuryprev-2018-043056

18. Kolakowsky-Hayner SA, Bellon K, Yang Y: Unintentional injuries after TBI: potential risk factors, impacts, and prevention. NeuroRehabilitation. 2016, 39:363-370. 10.3233/NRE-161368

19. Coronado VG, McGuire LC, Sarmiento K, Bell J, Lionbarger MR, Jones CD: Trends in traumatic brain injury in the U.S. and the public health response: 1995-2009. J Safety Res. 2012, 43:299-307. 10.1016/j.jsr.2012.08.011

20. Hyder AA, Wunderlich CA, Puvanachandra P, Gururaj G, Kobusingye O: The impact of traumatic brain injuries: a global perspective. NeuroRehabilitation. 2007, 22:341-353.

21. Majdan M, Plancikova D, Brazinova A, Rusnak M, Nieboer D, Feigin V, Maas A: Epidemiology of traumatic brain injuries in Europe: a cross-sectional analysis. Lancet Public Health. 2016, 1:e76-e83. 10.1016/S24682667(16)30017-2

22. Leibson CL, Brown AW, Ransom JE, Diehl NN, Perkins PK, Mandrekar J, Malec JF: Incidence of traumatic brain injury across the full disease spectrum. Epidemiology. 2011, 22:836-844.

23. Coronado VG, Xu L, Basavaraju SV, et al.: Surveillance for traumatic brain injury-related deaths--United States, 1997-2007. MMWR Surveill Summ. 2011, 60:1-32.

24. Ecola L, J Ringel, K Connor, et al.: Costs and Effectiveness of Interventions to Reduce Motor Vehicle-Related Injuries and Deaths: Supplement to Tool Documentation. Santa Monica, CA: RAND Corporation. 2018,

25. NYS Department of Health, Bureau of Occupational Health and Injury Prevention . (2014). https://www.health.ny.gov/statistics/prevention/injury_prevention/traffic/.

26. Olson Z, Staples JA, Mock CN, et al.: Helmet regulation in Vietnam: Impact on health, equity, and medical impoverishment. Injury Prevention and Environmental Health. 2016, 22: 10.1136/injuryprev-2015-041650

27. Cassidy JD, Carroll L, Peloso P, Borg J, von Holst H, Holm L: Incidence, risk factors and prevention of mild traumatic brain injury: results of the who collaborating centre task force on mild traumatic brain injury. J Rehabil Med. 2004, 36:28-60. 10.1080/16501960410023732

28. Cusimano MD, Zhu A: Systematic review of traumatic brain injuries in baseball and softball: a framework for prevention. Front Neurol. 2017, 8:492. 10.3389/fneur.2017.00492

29. Gilchrist MD, Thomas KE, Wald M, Langlois J: Nonfatal traumatic brain injuries from sports and recreation activities - United States, 2001-2005. MMWR. 2007, 56:733-737.

30. Parker EM, Gilchrist J, Schuster D, Lee R, Sarmiento K: Reach and knowledge change among coaches and 
other participants of the online course: "concussion in sports: what you need to know". J Head Trauma Rehabil. 2015, 30:198-206. 10.1097/HTR.0000000000000097

31. Baldwin G, Breiding M, Sleet D: Using the public health model to address unintentional injuries and TBI: A perspective from the Centers for Disease Control and Prevention (CDC). NeuroRehabilitation. 2016, 39:345349. 10.3233/NRE-161366

32. Lee R: The CDC's STEADI Initiative: promoting older adult health and independence through fall prevention. Am Fam Physician. 2017, 96:220-221.

33. Casey M, Parker M, Winkler G, et al.: Lessons learned from implementing CDC's STEADI falls prevention algorithm in primary care. Gerontologist. 2017, 57:787-796. 10.1093/geront/gnw074

34. Brenner A, Homaifar Y, Adler E, et al.: Suicidality and veterans with a history of traumatic brain injury: precipitating events, protective factors, and prevention strategies. Rehabil Psychol. 2009, 54:390-397. 10.1037/a0017802

35. Suffoletto B, Wagner AK, Arenth PM, Calabria J, Kingsley E, Kristan J, Callaway CW: Mobile phone text messaging to assess symptoms after mild traumatic brain injury and provide self-care support: a pilot study. J Head Trauma Rehabilitation. 2013, 28:302-312. 10.1097/HTR.0b013e3182847468

36. Faul M, Xu L, Wald MM, Coronado VG.: Traumatic Brain Injury in the United States: Emergency Department Visits, Hospitalizations and Deaths 2002-2006. Atlanta (GA): Centers for Disease Control and Prevention, National Center for Injury Prevention and Control. 2010. https://www.cdc.gov/traumaticbraininjury/pdf/blue_book.pdf

37. AAA Foundation for Traffic Safety. Preventing Road Rage: Anger Management for Drivers: Videocassette . (1998). https://newsroom.aaa.com/wp-content/uploads/2016/07/AAAFTS-Road-Rage-Brochure.pdf.

38. Bowles, J. Zendrive puts the skids under traffic fatalities . (2019). https://diginomica.com/zendrive-says-bigdata-eliminate-traffic-fatalities-really.

39. Forecasting Dangerous Driving to Prevent Crashes. (2017). https://zendrive.com/blog/forecastingdangerous-driving/.

40. Kuntzman G, Colon D, Baxandall P, et al.: Carpocalypse Now: Driving Is On The Rise Even As Lockdown Remains in Place. 2020, https://nyc.streetsblog.org/2020/05/14/carpocalypse-now-driving-is-on-the-riseeven-as-lockdown-remains-in-place/.

41. Near-real-time Daily VMT for 3,000+ U.S. Counties. (2020). https://www.streetlightdata.com/VMT-monitorby-county/.

42. Goodyear S, Blumgart J: Cities are starting to report big declines in car crashes, but increases in speeding . April 16, 2020,

43. New York City Council and Mayor de Blasio Announce Plans to Implement up to 100 Miles of Safe Streets. (2020). https://council.nyc.gov/press/2020/04/27/1943/.

44. Anstey KJ, Windsor TD, Luszcz MA, Andrews GR: Predicting driving cessation over 5 years in older adults: psychological well-being and cognitive competence are stronger predictors than physical health. J Am Geriatr Soc. 2006, 1:121-126. 10.1111/j.1532-5415.2005.00471.x

45. Kuntzman, G. SPEED DEMONS: The Scourge of Reckless Driving is Way Worse Than We Thought . (2020). Accessed: June 13, 2020: https://nyc.streetsblog.org/2020/04/13/speed-demons-on-steroids-do-our-leaderseven-care-about-reckless-drivers-right....

46. Fox GK, Bowden SC, Smith DS: On-road assessment of driving competence after brain impairment: review of current practice and recommendations for a standardized examination. Arch Phys Med Rehabil. 1998, 79:1288-1296. 10.1016/s0003-9993(98)90277-5

47. Hartnett KP, Kite-Powell A, DeVies J, et al.: Impact of the COVID-19 Pandemic on Emergency Department Visits - United States, January 1, 2019-May 30, 2020. Morb Mortal Wkly Rep. 2020, 69:699-704. 10.15585/mmwr.mm6923e1

48. Preliminary Estimate of Excess Mortality During the COVID-19 Outbreak - New York City, March 11-May 2, 2020. MMWR Morb Mortal Wkly Rep. 2020, 69:603-605.

49. Feuer, W. Doctors worry the coronavirus is keeping patients away from US hospitals as ER visits drop: 'Heart attacks don't stop'. Accessed: June 16, 2020: https://www.cnbc.com/2020/04/14/doctors-worry-thecoronavirus-is-keeping-patients-away-from-us-hospitals-as-er-visits....

50. Deffenbacher L, Deffenbacher M, Lynch S, et al.: Anger, aggression and risky behavior: a comparison of high and low anger drivers. Behav Res Therapy. 2003, 41:701-718. 10.1016/s0005-7967(02)00046-3 